\title{
Study on Neo-ecologism Value Construction
}

\author{
Wanxian $\mathrm{Li}^{1, \mathrm{a}}$ \\ ${ }^{1}$ School of Public Administration Hebei University of Economics and Business Shijiazhuang, China \\ ${ }^{a}$ Email: 1913418097@qq.com
}

\begin{abstract}
Neo-ecologism is one the hot topic in current study in both science and social science. However, It is hardly to find a clear concept, especially on the value level. The recent theory of Ecologism made up the value leak of modernity but lack of generative theoretical background. Therefore, the framework of Neo-ecologism can be set up by combining Ecologism theory with Chinese traditional ecological wisdom of Generative Holism to meet the current world demands for human sustainable development and the pursue for harmonious coexistence, win-win prospects and common prosperity between man and nature.
\end{abstract}

Keywords: Neo-Ecologism, value construction, ecological civilization

\section{INTRODUCTION}

Although Ecological Civilization has become a common view and the development tendency in the world, there are still some confusion in both theory and practice: what choice to make between ecological center and human center at the value level so as to realize the harmony between Man and nature? How to coordinate effectively the relationship between economy development and the biological environment protection so as to maintain the human's ever-rising material and cultural needs at the premise of improving biological environment at the social level? How to release scientific research from the bondage of positivism and utilitarianism so as to push the mutual progress of truth discovery and technology innovation? Obviously the above perplexes directly impact the historical process of ecological civilization, while the traditional theory of biology could not give the right answer. Therefore, a new word standing high in popular favor turns out as Neo-ecologism in both theoretical and practical fields. However, there is no definite concept toward Neo-ecologism till now. According to Gengshen $\mathrm{Hu}$ (2019), Neo-ecologism is to add the word "Neo" to the word "Ecologism" in order to show its difference and the creation on the original basis. Simply to say, it is a combination of western idea of ecology with eastern ecological wisdom. ${ }^{[1]}$

\section{ECOLOGISM REVIEW}

In order to solve the ecological crisis, the western ecologists put forward the thorough innovation on the world view, value, epistemology and methodology. They proposed that the human should establish the world view of Organic Holism. As David Griffin (1998) stated that all units in reality are inherently connected, and all units and individuals are composed of relationships. ${ }^{[2]}$ On the value level, they emphasize that nature's intrinsic value should be affirmed. Ervin Laszlo (1985) proposed to see the world in a systematic point of view. All systems have value and intrinsic value. They are all manifestations of nature's strong pursuit of order and regulation, and manifestations of nature's goal orientation, self-maintenance, and self-creation. ${ }^{[3]}$ David further pointed out that Postmodern science should not separate matter from consciousness, nor from facts, meaning, and value. Science is, therefore, inseparable from an inner moral view, and truth and virtue are parts of science. ${ }^{[4]}$ Methodologically they oppose "reductionism" and advocates "holistic methodology", and "ecology does not reject analysis. It embraces and applies all modern, rigorous analytical techniques, but it neither stays on analysis nor advocates objective, indifferent analytical values. It contains and transcends the analysis in a holistic approach that is essential to the task of its concept. ${ }^{[5]}$ Therefore, the ecologists have basically overcome the defects of human centrism and constructed a relatively perfect ecological theoretical framework. However, it is this perfection or idealization that has been widely questioned. On the one hand, it is poorly practical. As the custodian and spokesperson of nature, human beings cannot give up or reduce their pursuit of a better life for the optimization of the 
ecological environment. On the other hand, as an ecological civilization, Ecologism still lacks the ideological basis of "generative theory".

\section{NEO-ECOLOGISM VALUE CONSTRUCTIOn}

In fact, Chinese president, Xi Jinping's "Two Mountains Theory" has given "Neo-ecologism" the practical interpretation and theoretical enlightenment: "Green mountains and clear water are equal to mountains of gold and silver". It not only provides a practical goal for the construction of ecological civilization, namely to develop economy in the ecological civilization construction, but also outlines the "new ecology" basic theoretical content, namely harmonious coexistence between man and nature, mutual progress and double win-win. What's more, in order to achieve this goal, he pointed out in the report to the 19th CPC National Congress that "man and nature are a life-community, and human beings must respect, conform to and protect nature". Man and nature is the life-community thought inherited the Chinese ecological feelings of "unity of man and nature", embodies the core of Chinese traditional culture "Tao" concept: "Tao" is a preset for the natural reality already existed before the heaven and earth and moving according to their own rules, "independent and not change, functions universally without lapse." (Tao Te Ching • Chapter 25). Therefore, Tao is regarded as the ultimate body of creation and the metaphysical rule governing natural and social development. "The way of Tao is like stretching a bow. The top is pulled down, The bottom is pulled up. Excess string is removed, where more is needed. The Way of Tao, to remove where there is excess, and add where there is lack." (Chapter 77). Man is a part of nature, and the human ecosystem is a subsystem of the large systems of nature. Man and nature share a common destiny: mutual glory, mutual loss. Therefore, human beings should respect nature, have awe and gratitude for nature; Conform to nature, and request people to conform to the objective laws of nature, because humanity obeys the Tao of nature. If the human violates nature, "the harm to nature will eventually hurt human itself, which is an irresistible law" (Xi Jinping, 2016 at the 19th CPC National Congress).This is also the idea of "karma" in Chinese traditional culture. It can be seen that the "Neo-ecologism" in the Chinese context should be "An ecological civilization form of harmonious coexistence, win-win and common prosperity based on the pursuit of the idea of a community of shared future and the ideal of the unity of man and nature". This concept includes the following connotation and functions:

(1) At the concept level, it shows that man and nature are a life-community. The human is one part of nature. Nature exists before human beings and has its own creativity. It not only creates all kinds of biological species and the whole ecosystem, but also creates an environment and conditions suitable for life survival. It not only breeds humans, but also provides the information necessary for the survival of human development. Man is born because of nature, and the relationship of man and nature is symbiosis, with shared destiny. Man exists with the existence of nature and die with the demise of nature. Traditional Chinese philosophy regards man and nature as a life community and moral community, and takes the harmony between man and nature as the highest ideal. As Lao Tzu said, "Humans follow the earth, the earth follows the heaven, the heaven follows the law, and the law follows nature itself. " (Tao Te Ching • Chapter 25). The universe is a large ecosystem, the Earth or the human is one of the small ecosystems, and the two are essentially interlinked. Small systems are subject to large systems, and humanity is subordinated to the law. Human activities should conform to the laws of nature to achieve the harmony between man and nature. The Neo-ecologisml concept also provides strategic ideological guidance for economic activities. Unlike industrial civilization, economy limited to the current interests, it takes the development and continuation of human and natural life community as the premise of economy, It is based on realistic demand and focus on the global, long-term ecological development strategic economy. Otherwise it will lead to the current small profit but overall loss of ecological benefits.

(2) At the value level, it not only affirms the intrinsic value of nature, but also emphasizes the value of man and its responsibility to nature, especially clarifies the ultimate value care of "the unity of man and nature". Since man and nature are a life community, then the highest level and best state of communication between man and nature could be a unified whole. As President $\mathrm{Xi}$ Jinping said at the opening ceremony of the Horticultural Exposition: "Beautiful China is the home of the Chinese nation's survival and development. It has nurtured the splendid civilization of the Chinese nation for more than 5,000 years and created the lofty pursuit of the unity of man and nature." Ding Yuanming (2002) studied the Taoist scientific spirit and humanistic spirit and concluded that this thinking way of "union with Tao" represents the metaphysical thinking toward human ultimate care, demonstrating that only in the recognition of integrating with nature people can surpass the real troubles, and put his life in the flow of the universe without worry. ${ }^{[6]}$ In fact, the "the unity of nature and man" is not only the lofty pursuit of the Chinese nation, but also the common dream of many famous scientists in the world. Einstein referred to his psychological attitude the same as other scientists such as Kepler and Newton towards the nature of the universe (Tao) as "Cosmic religious feeling", for the reason why to use the word "religion", Einstein 
explained, "There are no better words to express (our) trust on the essence of reason of nature" [7]; Joseph Lee, a scientist and scientific historian, called "Tao learning " as "internal and unborn science in the most full sense"; Physicists Yukawa, Kapra believe, Taoist thoughts on the unity of man and nature, not only enlightens the physical world observed by quantum mechanical theory, but also the most profound and perfect survival wisdom. Yukawa even proposed the concept of "Tao of Physics" in $1964 .{ }^{[8]}$.

(3) At the theoretical level, the view of a community of shared future puts an end to the long-standing struggle between "human centrism" and "nature centrism", Corrects human centrist's binary opposition thinking of subject and object as well as the modern thoughts of one-sided believe in their ability of science and technology that can solve all problems and make clear the systematic way of thinking "what kind of role does human play in nature". It sets up a new ecological and ideological basis and epistemology paradigm for science and technology. As a community with a shared future, man and nature have the common goal, namely the harmony and continuation of the ecological community. Therefore, under the common goal orientation, people can define the boundaries of their roles so as to consciously adjust their behavior for the realization of the unity between man and nature; The new ecological concept introspected scientism of their rejection of metaphysics and its methods, attaching importance only to the rationality of tools and ignoring the highest value. It also re-examined the other extreme of postmodernism in criticizing rationalism: denying scientific rationality, eternal truth and ultimate value, and triggering the social trend of game life such as "everything is a game" and "present is everything" etc. ${ }^{[9]}$ Therefore, the new ecological concept not only clarified the fundamental purpose of harmonious for common prosperity of man and nature as well as its way of choice, but also corrected the disadvantages of ecological idealism and the negative impact of postmodernism's extremism on the contemporary attitude of life and lifestyle, and provides an ecological epistemology paradigm and methodological basis for scientific and technological innovation.

(4) At the practical level, it proposed the relationship of harmonious coexistence, win-win and common prosperity between man and nature, which could coordinate the contradiction between economic development and environmental protection in the social field. Xi Jinping made a clear description: "People are born because of nature, and man and nature are a symbiotic relationship. Ecology is a unified natural system and a natural chain for the interdependence of various natural elements. A good ecological environment is the foundation of human survival and health." This provides the theoretical basis and practical guide for social production and life, namely to arrange social and production activities based on ecological prosperity, including adhering to the law and local conditions for scientific planning, having scientific governance spirit, advocating simple and moderate, green and low carbon lifestyle, refuse luxury and waste, and form civilized and healthy lifestyle, let the green mountains create comprehensive benefits, achieve sustainable economic and social development." Neo-ecologism about harmony and coordination relation between man and nature also brings solutions to the modernity dilemmas, such as the choice for value rationality and tool rationality, purpose and means, truth and utility, ethics and logic etc. Under the concept of destiny community, any contradiction is relative, unity is inevitable. If a choice must be made in special circumstances, value, purpose, truth and ethics are always the first. This is the bottom line ethics in the economic field. "we would rather want clear waters and green mountains, not gold and silver mountains".

(5) At the regional culture level, it provides a value framework of culture identification. As the general concept of the relationship between man and nature, the life-community idea is also the value principle for the identification between different nations and different regional cultures. The culture difference among Beijing, Tianjing and Hebei province could be whittled away with the implementation of the National strategy on their coordinated development, especially with the era changes from industry civilization to ecological civilization, the former interest structure and culture barriers will surely collapse. The culture value of Neo-ecologism will be the common value of Beijing, Tianjin and Hebei province and at the same time, accompany the transition of thinking, living and behaving styles. Once the idea of life-community accepted by people of the three regions, they will change their role-position from ego-center to the community center, and their thinking style from individual to the whole as well as their behavior from self-interest orientation to community-interest orientation. Furthermore, the innovation of science and technology will breakthrough the local establishment by means of various associations and joint associations in the community, so as to truly realize the coordinated development of mutually beneficial cooperation and win-win sharing between the Beijing-Tianjin-Hebei region.

\section{CONCLUSION}

Above all, the concept of Neo-Ecologism coagulated both Western civilization and Eastern wisdom, as a transitional word in the era from industrial civilization to ecological civilization. Although it demonstrates its rationality and effectiveness in both theory and practice, it is after all a new exploration toward stepping out of 
the current dilemma brought by industrial civilization so as to realize the human sustainable development. Therefore, this paper is only to throw out a brick to attract a jade and hope more people would join in the discussion.

\section{REFERENCES}

[1] Gengshen $\mathrm{Hu}$, Neo-Ecologism and Neo-Ecologism Translation Viewpoint, Journal of Boyanghu, Vol.6, 2019, pp. 5-11. (In Chinese)

[2] [4][5]David Griffin, translated by Ji Ma, Post-modernism-----Reflection of Science Image, The Central Translation Press, China, 1998, pp. 151, 83-84, 148. (In Chinese)

[3]Ervin Laszlo, Seeing the World in A Systematic Way, Social Science Press China, Beijing, 1985, pp. 109.(In Chinese)

[6][8]Yuanming Ding, Taoist's Science Spirit and Humanity Spirit, Culture-History-Philosophy, Vol. 1, 2002, pp. 54-59. (In Chinese)

[7] Liangying Xu, Einstein's Collected Works, Vol. 1, The Commercial Press, Beijing, 1976, pp.526.(In Chinese)

[9] Zhu Han, Western Value System and Its Review, Journal of Nanchang Hangkong University (Social Science Version), Vol. 4, 2012, pp. 31-42. 